\title{
Editorial
}

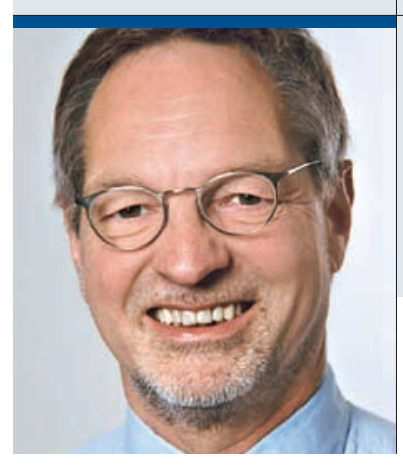

„Bloch wäre ein guter Präsident für den Frieden - leider haben

wir Krieg."

Dr. med. Walther Grohmann

Chefredakteur und niedergelassener Urologe, München

\section{Krieg und Frieden}

W enn in Zeiten, in denen keiner gerne die Pferde wechselt, der allseits als integer angesehene Präsident des Berufsverbandes der Urologen (BDU) Dr. Martin Bloch mit überwältigender Mehrheit und ohne Intrigenspiel in Düsseldorf nach nur einer Amtsperiode abgewählt wurde, so sind die Gründe dafür zu hinterfragen. Auch sein Nachfolger, Dr. Axel Schröder, muss diese vor Augen haben.

So erinnern wir uns mit einem gewissem Befremden an den BDU-Vorstand, als uns die Kassenärztlichen Vereinigungen erstmals das Regelleistungsvolumen (RLV) mitteilten. Nahezu zeitgleich erhielten die BDU-Mitglieder ein Schreiben, in dem verkündet wurde, dass es dem BDU-Präsidium dankenswerterweise gelungen sei, mit der „Ecclesia“ einen Versicherungsvertrag auszuhandeln. Die Basis fühlte sich jedoch auf den Arm genommen, denn auf eine Mitteilung des Präsidenten zur hochakuten RLV-Problematik musste sie sehr, sehr lange warten. Dies war auch durch den im aktuellen Tätigkeitsbericht des Präsidenten höchst ungeschickt angesprochenen Zeitaufwand für den Umgang mit der "Altlast“ zu Beginn seiner Amtsperiode nicht zu entschuldigen.

Ähnliches gilt für die Onkologievereinbarung: Wie es regional unterschiedliche RLVs gibt, so erfordert auch hier die Auslegung - ungeachtet der „zentralen“, handlungsbedürftigen Problematik - ein Verhandeln auf Länderebene. Hierbei waren einige urologische, auch BDU-unabhängige regionale Bündnisse erfolgreich. Dass der Präsident in seinem Tätigkeitsbericht diese Erfolge mit auf seine Fahnen schrieb, kam vor der Wahl nicht gut an und führte in der Versammlung zu heftigen Widersprüchen.

Symptomatisch waren schließlich auch die äußeren Umstände der Präsidentenwahl: Dass der Saal viel zu klein war, mag als Panne abgebucht werden. Dass aber der amtierende und der ehemalige DGU-Präsident wie der (ehemalige) Generalsekretär buchstäblich vor der geöffneten Türe stehen mussten, während gleichzeitig der BDU-Präsident über die gute Zusammenarbeit der beiden Verbände DGU und BDU berichtete, war kaum entschuldbar. So war es früher traditionelle und gute
Geste, dass der BDU-Präsident seinen langen Rechenschaftsbericht unterbrach, um dem DGU-Präsidenten das Wort zu erteilen.

Wie sagte doch ein Kollege zur Wahl: „Bloch wäre ein guter Präsident für den Frieden, aber leider haben wir Krieg". Jetzt haben wir also mit Schröder einen Kriegspräsidenten. Was sollen wir ihm auf den Weg mitgeben? Wir wünschen uns unter anderem mehr Bezug zur Basis und die notwendige - auch finanzielle - Stärkung der Landesverbände, wenn Verhandlungen nur auf Landesebene (siehe Auslegung der Onkologievereinbarung) möglich sind. Zentrale Probleme müssen, wenn erforderlich, zusammen mit der DGU bearbeitet werden, und zwar bevor das Kind in den Brunnen gefallen ist. Auch hier weiß die Basis meist schon früher und besser als die Kollegen im Elfenbeinturm über mögliche Folgen für die niedergelassene Praxis Bescheid. Und wir wünschen uns eine effektive Arbeit bei der Laienpresse: Nur abstrakte Zahlen emotionslos vorzutragen, wie es der scheidende BDU-Präsident auf der Pressekonferenz in Düsseldorf gemacht hat, war eine verschenkte Chance, der Publikumspresse unsere gute Arbeit als Urologen unter schwierigsten strukturellen Problemen nahezubringen.

Nicht vergessen sei die Wahl des 2. BDU-Vizepräsidenten: Kollege Plate kandidierte nicht mehr für seine Wiederwahl. Als sein ebenfalls im Osten ansässiger Nachfolger wurde per Akklamation Dr. Matthias Schulze gewählt. Leser der URO-NEWS kennen ihn als langjähriges, fachlich und berufspolitisch kompetentes Mitglied des Beirats unserer Zeitschrift.

So wünschen wir den neuen BDU-Präsidenten, dass sie Erfolg und Fortune in ihrem nicht einfachen neuen Amt haben.

Ihr

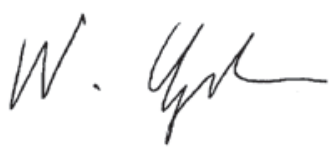

